\title{
AC 2012-3646: BUILDING A CLASSROOM CULTURE THAT PAVES THE WAY TO LEARNING
}

Dr. Brian Swartz P.E., University of Hartford

Brian Swartz is Assistant Professor of civil engineering at the University of Hartford. He received his degrees from the Pennsylvania State University, where he also taught for two years. He was a visiting faculty for one year at Bucknell University before joining the University of Hartford. He teaches courses in structural engineering and pursues research related to concrete bridges. 


\section{Building a Classroom Culture that Paves the Way for Learning}

Introduction

Most college-level teachers in engineering were educated, themselves, in their technical discipline, not in teaching. The teaching trade is learned on the job and often amidst pressure to do other things, specifically build research programs and serve the institution in various fashions. In this paper, the author shares lessons learned from the first five years in engineering education, hoping those experiences will help others starting their careers under similar circumstances. The paper combines the author's own experiences and anecdotal evidence with established research findings and long-held truths in teaching and learning to present several clear recommendations for the new college-level engineering instructor. The recommendations fall into five categories:

1. Establish rapport with the class

2. Articulate clear learning objectives for the course

3. Structure the content and delivery to facilitate learning

4. Involve students in class time

5. Hold students accountable for learning

The lessons learned and the recommendations summarized here have led the author towards implementing the "classroom flip" strategy. The paper concludes with a summary of ongoing work to evaluate the effectiveness of the flip approach.

\section{Establish Rapport with the Class}

Oftentimes students have a distorted perception of the educational process and the role of the teacher and learner in that process. They might hold the assumption that the teacher's job is to force learning to happen or that the classroom is somehow supposed to model the employeremployee relationship. Unfortunately, the approach of many students to their education has undoubtedly been soured by a poor instructor somewhere in their past, throwing their expectations of both the teacher and the learner off-base.

It is essential that the student understand his role in the classroom and also the instructor's. While there are times to model the employer-employee relationship, perhaps in a senior capstone course, the teacher is primarily present to facilitate the students' learning. Helping students to realize this, and to understand that theteacher has their best interests in mind and that all are "on the same team," is crucial. Citing parallels between the teacher in the classroom and a personal trainer or coach in athletics is one effective approach. The author has found that individual or small group meetings with the students very early in the course is sometimes a more appropriate setting to communicate this relationship than the lecture hall.

The teacher must also clearly communicate a genuine sense of caring for the students' learning. Being open, approachable, and patient are just some of the character traits that students are likely hoping to find in the instructor. Students tend to feel a more positive atmosphere for learning 
when they are able to develop a meaningful relationship with the instructor, so educators should avail themselves to such interaction and encourage relationships. Alexander Astin's research ${ }^{1}$ substantiates this point by noting, "the quality of interactions between students and instructors in and out of class was the factor that correlated most highly with almost every positive learning and attitude outcome considered." Others ${ }^{2,3}$ have also stated and validated the connection between positive student-faculty interaction and the students' intellectual commitment.

The instructor must communicate high expectations to the class. Failing to do so ensures that they meet the implied low expectations. Perhaps the best strategy, besides just articulating the expectations, is to lead by example. Instructors who hold themselves to high standards in their course delivery, prompt grading, attentiveness to student needs, and so forth cultivate an environment where students are well motivated.

Finally, the instructor should be sensitive to the fact that some students learn very differently than others. Furthermore, the personalities who go on to become professors tend to be intuitive learners while most engineering students are sensory learners ${ }^{4}$. This creates a teacher-learner gap that the instructor should strive to understand and overcome. A reasonable level of flexibility in the teaching methods used in the course should be offered once the needs of the students have been observed. Much has been written about learning styles, so duplication here is not warranted. The work of Felder and Silverman ${ }^{5}$ is one valuable reference.

\section{Articulate Clear Learning Objectives for the Course ${ }^{6}$}

Learning objectives are statements that clearly capture the intended outcome of the course, specifically detailing the skills or knowledge that students should matriculate towards during the progression of the course. The course learning objectives serve a few purposes, but most importantly they can act as an important guide for course development. Curriculum design, including choosing which content to include and in which order, should follow the objectives very closely. Clearly articulated objectives allow for straightforward prioritization of topics and allotment of time in the course.Furthermore, the choice of textbook and teaching styles, along with the class exercises and homework problems used, should clearly complement the course objectives.

The learning objectives should also be used in studying and assessment, both by the instructor and the student. The instructor should develop an assessment strategy that clearly and fairly measures the students' achievement of the objectives. Similarly, the student can use the list of objectives in preparing for exams and other assessments to guide her learning. By using the list of objectives as a study guide, nothing on the exam should come as a surprise to the student.

\section{Structure the Content and Delivery to Facilitate Learning}

Perhaps one of the instructor's most obvious tasks is structuring and delivering the course content. Presentation of the material in an organized and intentional sequence is paramount to effective pedagogy. 
First, people tend to learn material contextually ${ }^{7}$. Humans need to be able to relate newly learned information to previous knowledge in order to effectively understand and recall it. It is the instructor's job to frame the material for the course in its proper context. In engineering curricula, that often means tying the material to previously held knowledge or observations, perhaps from a demonstration.

The instructor must also set the context of the knowledge by establishing relevance and significance. Students learn best when they recognize the importance and the applicability of the material $^{8,9}$. Oftentimes the context of the detail within a larger problem statement can help establish relevance. Obviously real-world projects and case studies are also desirable. The instructor's contagious enthusiasm for the subject matter is another desirable trait.

When the content is actually delivered, it must be organized. It is not reasonable for the instructor to expect the student to stay organized and receive the information in proper context if the course material is delivered haphazardly. The instructor should strive for clear, concise lecture notes and handouts. Any figures or problem statements to be used in class should be available to the student in a manner that makes them easy to reference during class time. The instructor should also achieve the maximum time on task during the class period. Problem statements for example problems or figures that can be easily delivered to the student prior to class, rather than robotically rewriting them during class, should be distributed. The author uses a variation of the Board Notes approach ${ }^{10}$ taught by the ExCEed workshops to facilitate classroom organization.

The course content should include a healthy balance of concrete (data, facts) and abstract (theories, model equations) information. Many engineering students prefer concrete information and that is why class examples should begin with numerical values and build towards expressions that include algebraic variables ${ }^{11}$. The engineering education must find a balance between the theoretical background of the subject and the application of the knowledge.

Finally, key concepts should be carefully identified and highlighted. The author has adopted a strategy of thinking very carefully about the course content which should be learned and easily recalled for future learning and application. That content is differentiated from the facts and details that even the most intelligent student would not be able to memorize beyond the conclusion of the course. Those key concepts should be emphasized in the instruction, making sure that the students do not miss the most critical portion of the subject. The problem, in many cases, is that the concepts may be so obvious to the instructor that they are taken for granted. The instructor does not, in his/her own thinking, have trouble isolating the concepts from the details. But students have a much more difficult time separating the two, and can easily let the details overwhelm them to the point of missing crucial concepts. It falls on the instructor, then, to isolate the concepts and ensure essential learning.

\section{Involve Students in Class Time}

Passive lecturing does not prove to be especially effective ${ }^{4}$ for helping students reach the higher levels of learning ${ }^{12}$ often desirable in an engineering graduate. Therefore, it is important to actively involve students in the class time. 
Before specifically discussing active learning strategies, a few other points are warranted. First, the student must be led to invest in his own learning. It is not possible to force knowledge into the student, but many students might carry the misconception that it is possible, and that it is being done to them. Not so! The student must move beyond the passive receiver of information to an active learner of new knowledge. Secondly, while students often appreciate a certain level of predictability in class, it is essential that the use of class time be varied. Applying the same routine too frequently in class can quickly lead to mundane exercises that lose their effectiveness. Finally, remain focused on a mission to build in the students a desire for and an aptitude to pursue lifelong learning. Students will need to learn much more beyond their college education in order to become effective engineers. Very little of that knowledge learned beyond degree work will come from a classroom environment. Instead they will be seeking new knowledge on their own, learning from publications and research data, citing their own experiences, or investigating new ideas collaboratively with other professionals. That style of learning should, at least at times, be simulated in the classroom so that students can practice learning without formal instruction and so that they develop a thirst for such learning.

There are numerous approaches to achieving active learning in the classroom that have been demonstrated with reasonable levels of success ${ }^{13}$. It is largely beyond the scope of this paper to introduce active learning strategies, but the work of Prince ${ }^{13}$ provides a nice summary. The point will be made here, based on the author's experiences, that the active learning strategies chosen should be natural, considering the course content and the personalities of the students and the instructor. If the teaching method is "forced", in other words if an active learning exercise is being used just for the sake of using an active learning exercise, its effectiveness is lost.

The instructor's experience suggests that often a well-planned, effectively-delivered, "active lecture" can be just as effective as any "active learning strategy." When the course content or the student demand calls for lecturing, the delivery should be such that students are constantly asked to think and not only record information dealt to them. This can be achieved if 1) the content is very intentionally organized so that it clearly builds on prior knowledge and moves towards a clear goal, and 2) if a dialogue is maintained such that students are constantly providing feedback and asking or answering questions.

\section{Hold Students Accountable for Learning}

Students, as a whole, seem to struggle to hold themselves accountable for their own learning. That responsibility falls to the instructor. Assessment should not be entirely tied to grades and "points" as that tends to shift the focus from education to grade achievement. Sometimes holding students accountable to each other is an effective strategy. Such a relationship can be accomplished in various cooperative learning models ${ }^{14}$, jigsaw strategies, or even group quizzes.

Inevitably student learning must be assessed and grades must be assigned. For some students, this process, alone, sufficiently holds them accountable to completely assignments and learning the course content, at least well enough for adequate performance on exams. 
The instructor must bear some responsibility in the assessment process. First, the process should be seen as useful for more than just grade determination. There should be a genuine desire to help the student recognize what she knows and does not know, so thatshe can appropriately focus and prioritize their studies ${ }^{2}$. For this reason assessment should be tiered, with the same skills evaluated, perhaps, on a homework assignment, quiz, and exam. In order for the assessment to serve this purpose, particularly those lower-tier assessments, the feedback must be constructive and timely. If the student is left waiting a week to receive a graded homework assignment, the value of that feedback is compromised by the wait time. In the author's observation, students reviewing a graded assignment that was slow to be returned focus more on the details, and on judging whether they feel the assignment was scored fairly, and less on correcting fundamental misunderstanding of concepts. The reason for this phenomenon seems simple. First, a stretch of time has passed since the student first did the work and she probably does not specifically recall all the thought processes used when originally preparing the submission and all the concepts that she thought were applied correctly. It takes a lot effort on the student's part to return to the frame of mind of the assignment, think through the process used, and fill in gaps in learning indicated by the grading comments. Remember that by the time the student reviews the graded assignment, she has rightly shifted her focus to preparing the submission of the next assignment, probably related to a different topic.

The instructor's other key responsibility is to develop thoughtful, meaningful, and fair assessments. Again a focus on the course objectives is helpful towards this end. Lower-tier assessments might require recall of facts and details, but as the course progresses the assessment should target higher levels of learning ${ }^{12}$ and proper application of concepts. The assessment should challenge the student, but not exasperate or frustrate her. Ultimately, the student's achievement of the course objectives should be assessed. So long as the course is well structured to nurture the student towards those objectives, and it is achievement of those objectives that is measured, the student should easily agree that the assessment was fair.

\section{Future Direction: A Work In Progress}

Careful consideration of the lessons learned as summarized in this paper has led the author towards considering a new approach to teaching, coined the "classroom flip" strategy by some ${ }^{15,16}$. In this model much of the traditional lecture content is moved outside the class time and delivered via readings, videos, and provided notes. The student is responsible for reviewing the material prior to class. The class time can then be used more effectively for practicums and other active learning exercises, with the instructor available to summarize and clarify key concepts that may have been missed in the students' out-of-class preparation. Therefore the instructor's class presentation is geared specifically to the students' needs for learning.

The classroom flip approach is attractive for several reasons. First, it encourages the student to become a more self-directed learner. The student has the ability to practice, within a controlled setting, the skills that will be needed to sustain the lifelong learning essential in the engineering disciplines. The focus in this model shifts from the instructor to the student, with the student ideally learning to take responsibility for his own education and becoming less expectant of an instructor to force knowledge upon him - a phenomenon that never was possible but seemed to be the expectation of some students. 
A flipped classroom also allows for just-in-time learning because the instructor is available during the class time to help students work through a new idea while working on a meaningful problem just at the point when he becomes stuck. This helps to establish the context of the newly learned concept, and clarifies the need-to-know that motivates the student towards a deeper understanding.

Moving traditional lecture material outside of class allows the instructor to integrate several active learning strategies which have been shown successful ${ }^{13}$ while not sacrificing the amount of content that can be covered. Some fear that active learning exercises use a lot of valuable class time and that they compromise the instructor's ability to cover all of the material. This may be true if the instructor wishes to cover all of the material via traditional lecture, but if coverage of some content can be moved outside the class, more class time is made available without a loss of content.

The classroom flip strategy enables immediate feedback to the students, so they know whether or not they are applying concepts correctly. Since the students will be actively attempting to apply new concepts to meaningful problems during class time, the instructor can immediately confirm correct application and redirect incorrect thinking.

The author will evaluate the merits of a classroom flip in the upcoming semester while teaching two parallel sections of sophomore-level Mechanics of Materials. Both sections, of approximately 20 students each, will be taught identical content, but the teaching strategies will vary. One of the sections will be taught using a traditional lecture method, followed by frequent out-of-class follow up homework assignments. The second section will be taught using the classroom flip strategy, with much of the lecture content delivered via readings and videos. The students in both sections will be evaluated using identical assessments. A pretest will be given to all students so that knowledge of pre-requisite material can be gauged and used as a baseline when comparing the two sections.

The study will also attempt to capture perceptions of the workload incurred when the "flipped" method of delivery is used, both on the students and on the faculty. In theory, if the same work is accomplished over the course of the semester, the workload on the student should not change substantially. The expectations on their time prior to class will increase, but that should be offset by having less work to do following up on a class (i.e. traditional homework). Development of a course in the "flipped" format is used will undoubtedly be time-consuming for the faculty member. The author aims to provide recommendations, based on this experience, to help others work efficiently in developing courses in this model and prepare materials that can be easily used in subsequent course offerings.

\section{Conclusion}

The educational process, and the instructor's role in it, is complicated and perhaps best learned via experience. The author has learned much in the first five years of teaching engineering and can say that establishing a strong rapport with the class, articulating clear learning objectives,

delivering well-structured content, actively involving students in learning, and holding students 
accountable for their learning are keys to success. Those lessons have led the author to consider a classroom flip strategy that lends itself well to implementing all of those recommendations.

\section{Bibliography}

1. A.W. Astin, What Matters in College: Four Critical Years Revisited. Jossey-Bass, San Francisco, 1993.

2. A.W. Chickering and Z.F. Gamson, "Seven Principles for Good Practice in Undergraduate Education." AAHE Bulletin, March 1987.

3. R.C. Wilson, J.G. Gaff, E.R. Dienst, L. Wood, and J.L. Barry, College Professors and Their Impact upon Students. New York: Wiley, 1975.

4. R.M. Felder, D.R. Woods, J.E. Stice, and A. Rugarcia, "The Future of Engineering Education: Teaching Methods That Work." Chemical Engineering Education 34(1), 26-39 (2000).

5. R.M. Felder and L.K. Silverman, "Learning and Teaching Styles in Engineering Education." Engineering Education, 78(7), 674-681 (1988).

6. N.E. Gronlund, How to Write and Use Instructional Objectives, $6^{\text {th }}$ Ed. Prentice-Hall, Upper Saddle River, 2000.

7. J.M. Haile, "Toward Technical Understanding." (i) "Part 1. Brain Structure and Function." Chem. Engr. Education, 31(3), 152-157 (1997). (ii) "Part 2. Elementary Levels." Chem. Engr. Education, 31(4), 214219 (1997). (iii) "Part 3. Advanced Levels." Chem. Engr. Education, 32(1), 30-39 (1998).

8. W.J. McKeachie, Teaching Tips: Strategies, Research, and Theory for College and University Teachers, $10^{\text {th }}$ Ed., Houghton Mifflin, Boston, 1999.

9. P. Wankat and F.S. Oreovicz, Teaching Engineering, McGraw-Hill, New York, 1993.

10. S.J. Ressler, R.W. Welch, and K.F. Meyer, "Organizing and Delivering Classroom Instruction.” Journal of Professional Issues in Engineering Education and Practice, 130(3), 153-156 (2004).

11. R.M. Felder, "Reaching the Second Tier: Learning and Teaching Styles in College Science Education." Journal of College Science Teaching, 23(5), 286-290 (1993).

12. B.S. Bloom. Taxonomy of Educational Objectives, Longman, New York, 1956.

13. M. Prince, "Does Active Learning Work? A Review of the Research." Journal of Engineering Education, 93(3), 223-231 (2004).

14. P.C. Blumenfeld, R.W. Marx, E. Soloway, and J. Krajcik, "Learning with Peers: From Small Group Cooperation to Collaborative Communities." Educational Researcher, 25(8), 37-40 (1996).

15. C. Demetry, "Work in Progress - An Innovation Merging 'Classroom Flip' and Team-Based Learning." Proceedings of $40^{\text {th }}$ ASEE/IEEE Frontiers in Education Conference, Oct 27-30, 2010.

16. R. Toto and H. Nguyen, "Flipping the Work Design in an Industrial Engineering Course." Proceedings of $39^{\text {th }}$ ASEE/IEEE Frontiers in Education Conference, Oct 18-21, 2009. 